\title{
Translabyrinthine microsurgical resection of small vestibular schwannomas
}

\author{
Marc S. Schwartz, MD, ${ }^{1,3}$ Gregory P. Lekovic, MD, PhD, ${ }^{1}$ Mia E. Miller, MD, ${ }^{2}$ \\ William H. Slattery, ${ }^{2,4} \mathrm{MD}$, and Eric P. Wilkinson, MD2,3 \\ Departments of ${ }^{1}$ Neurosurgery and ${ }^{2}$ Neurotology, House Clinic, Los Angeles; ${ }^{3}$ Huntington Medical Research Institutes, \\ Pasadena; and ${ }^{4}$ Department of Otolaryngology, University of Southern California, Los Angeles, California
}

\begin{abstract}
OBJECTIVE Translabyrinthine resection is one of a number of treatment options available to patients with vestibular schwannomas. Though this procedure is hearing destructive, the authors have noted excellent clinical outcomes for patients with small tumors. The authors review their experience at a tertiary acoustic neuroma referral center in using the translabyrinthine approach to resect small vestibular schwannomas. All operations were performed by a surgical team consisting of a single neurosurgeon and 1 of 7 neurotologists.
\end{abstract}

METHODS Data from a prospectively maintained clinical database were extracted and reviewed. Consecutive patients with a preoperative diagnosis of vestibular schwannoma that had less than $1 \mathrm{~cm}$ of extension into the cerebellopontine angle, operated on between 2008 and 2013, were included. Patents with neurofibromatosis Type 2, previous treatment, or preexisting facial weakness were excluded. In total, 107 patients were identified, $74.7 \%$ of whom had poor hearing preoperatively.

RESULTS Pathologically, $6.5 \%$ of patients were found to have a tumor other than vestibular schwannoma. Excluding two malignancies, the tumor control rates were $98.7 \%$, as defined by absence of radiographic disease, and $99.0 \%$, as defined by no need for additional treatment. Facial nerve outcome was normal (House-Brackmann Grade I) in $97.2 \%$ of patients and good (House-Brackmann Grade I-II) in 99.1\%. Complications were cerebrospinal fluid leak (4.7\%) and sigmoid sinus thrombosis $(0.9 \%)$, none of which led to long-term sequelae.

CONCLUSIONS Translabyrinthine resection of small vestibular schwannomas provides excellent results in terms of complication avoidance, tumor control, and facial nerve outcomes. This is a hearing-destructive operation that is advocated for selected patients.

https://thejns.org/doi/abs/10.3171/2017.2.JNS162287

KEY WORDS vestibular schwannoma; microsurgery; translabyrinthine; intracanalicular; cerebellopontine angle

$\mathrm{T}$ HE translabyrinthine (TL) approach to the cerebellopontine angle was first described by Panse in the late nineteenth century. ${ }^{38}$ This approach did not truly become technically feasible until it was reintroduced in the early 1960s by William House, who brought the operating microscope to otologic and skull base surgery. Soon after, House and Hitselberger demonstrated that use of the TL approach reduced the mortality of vestibular schwannoma (VS) surgery to under three percent. ${ }^{27,28}$

Improvements in diagnostic techniques, including the development of MRI, led over time to the frequent diagnosis of smaller tumors. ${ }^{52}$ It has long been recognized that outcomes from VS surgery of smaller tumors, in terms of complications and facial nerve outcomes, are superior to those of larger tumors. ${ }^{37,55,59}$ With the introduction of newer technologies, such as facial nerve monitoring, and refinements in technique, outcomes have been improved further. ${ }^{6,36,45}$

Concurrent with improvements in surgical techniques, alternative treatment options for VS, such as stereotac-

ABBREVIATIONS AAO-HNS = American Academy of Otolaryngology-Head and Neck Surgery; $\mathrm{CPA}=$ cerebellopontine angle; $\mathrm{CSF}=$ cerebrospinal fluid; $\mathrm{HB}=\mathrm{House}-$ Brackmann; IAC = internal auditory canal; PTA = pure-tone average; $\mathrm{QOL}=$ quality of life; $\mathrm{TL}$ = translabyrinthine; $\mathrm{VS}$ = vestibular schwannoma; WRS = word recognition score.

SUBMITTED August 30, 2016. ACCEPTED February 9, 2017.

INCLUDE WHEN CITING Published online August 18, 2017; DOI: 10.3171/2017.2.JNS162287. 
tic irradiation, have been introduced. ${ }^{30,32}$ Furthermore, the natural history of VS has become better understood, so that it is now clear that many tumors do not grow or grow very slowly. ${ }^{50}$ Patients are thus faced with a variety of treatment options, including microsurgery, stereotactic radiotherapy or radiosurgery, and observation.

We present a consecutive series of patients with small VSs resected via the TL approach. This approach allows direct exposure of tumors, including the ability to directly visualize the entire tumor and its interface with the facial nerve both medially and laterally. The need for brain retraction or manipulation is eliminated. The TL approach is, however, destructive of hearing since it is necessary to resect a portion of the otic capsule to expose the tumor.

\section{Methods}

We performed a review of data that had been generated and maintained in a prospective, ongoing database developed for purposes of clinical patient care and study. Prior to undertaking this review, an institutional review board waiver had been obtained (St. Vincent Medical Center). All consecutive patients undergoing TL resection of small tumors with the preoperative diagnosis of VS were included, with the exception of patients with neurofibromatosis Type $2(\mathrm{n}=2)$, those who had undergone previous treatment $(n=3)$, and those with preoperative abnormal facial nerve function $(n=1)$. Patients were operated on by surgical teams consisting of a single neurosurgeon (M.S.S.) and 1 of 7 neurotologists during a 6-year period, from 2008 through 2013. Small VSs were defined as purely intracanalicular tumors or tumors with a cerebellopontine angle (CPA) size less than or equal to $1.0 \mathrm{~cm}$. Both overall tumor dimension, including both internal auditory canal (IAC) and CPA portions, and greatest dimension in the CPA alone were recorded.

\section{Population}

One hundred seven patients who met the inclusion criteria were operated on during the study period. In addition to appropriate MRI, all patients underwent preoperative audiometric testing, including pure-tone average (PTA) and word recognition score (WRS). Hearing was categorized by using the American Academy of Otolaryngology-Head and Neck Surgery (AAO-HNS) classification system and by using current clinical standards. ${ }^{23,33}$ Facial nerve function was also assessed and graded from I to VI according to the House-Brackmann (HB) scale. ${ }^{26}$

Demographic data regarding patient and tumor characteristics are presented in Table 1. Thirty-seven tumors were entirely intracanalicular, while 70 had extension into the CPA. Only 8 patients $(7.5 \%)$ had good hearing (AAOHNS Class A), and only 27 patients (25.2\%) had serviceable hearing (AAO-HNS Class A or B) (Fig. 1).

\section{Procedures}

Our operative technique of TL resection of VS has previously been described. ${ }^{49}$ Specific adaptions of the technique to small tumors are demonstrated in the associated video (Video 1).

VIDEO 1. Video showing resection of small VSs via the TL route.
TABLE 1. Patient and tumor characteristics

\begin{tabular}{lc}
\hline \multicolumn{1}{c}{ Characteristic } & Value \\
\hline No. of patients & 107 \\
\hline Median age (SD; range) & $54.5(12.7 ; 9-76)$ \\
\hline Sex & $48(44.9 \%)$ \\
\hline Male & $59(55.1 \%)$ \\
\hline Female & \\
\hline Side & $40(37.4 \%)$ \\
\hline Left & $67(62.2 \%)$ \\
\hline Right & $1.0(0.2 ; 0.4-1.3)$ \\
\hline Tumor size (cm) & \\
\hline Intracanalicular tumors ( $n=37)$ & $1.5(0.2 ; 1.1-2.0)$ \\
\hline Median max dimension (SD; range) & $0.7(0.2 ; 0.3-1.0)$ \\
\hline Tumors with CPA extension ( $n=70)$ & \\
\hline Median maximum dimension (SD; range) & $13(68.2 \%)$ \\
\hline Median CPA dimension (SD; range) & $8(7.5 \%)$ \\
\hline All tumors & $19(17.8 \%)$ \\
\hline Median maximum dimension (SD; range) & $1.3(6.5 \%)$ \\
\hline Preoperative hearing class & \\
\hline AAO-HNS A & \\
\hline AAO-HNS B & \\
\hline AAO-HNS C & \\
\hline AAO-HNS D & \\
\hline
\end{tabular}

Included are a tumor with 1-cm extension in the CPA and an intracanalicular tumor impacted in the fundus of the IAC. Copyright Marc S. Schwartz, House Clinic, Neurosurgery. Published with permission. Click here to view.

Continuous facial nerve monitoring using the XomedNIM (Medtronic) was used for all cases. Following surgery, patients were observed overnight in the intensive care unit and began mobilization on the 1st postoperative day. Patients were discharged from the hospital after meeting discharge criteria, including weaning of all parenteral medication, safe ambulation, and tolerance of diet. Disposition to home/hotel or to inpatient rehabilitation was recorded, as were any complications.

Immediate postoperative facial nerve function was assessed on the day of surgery. Facial nerve function was further assessed on each hospital day and at each point of patient contact during the postoperative period. For patients with a decline in facial nerve function, the "worst" postoperative grade was recorded. For any patient in whom normal facial nerve function was maintained throughout the entire postoperative period, final facial nerve grade was recorded at 1 month. For any patient with abnormal facial nerve function, the final grade was recorded either at the time of return to normal function or at 1 year postoperatively.

As is our standard practice, MRI was not performed in the immediate postoperative period unless there were specific clinical indications. It is our usual protocol to recommend MRI surveillance at 1 year and 5 years postoperatively. In cases of unusual pathology, incomplete tumor resection, or ambiguous imaging findings, MRI 


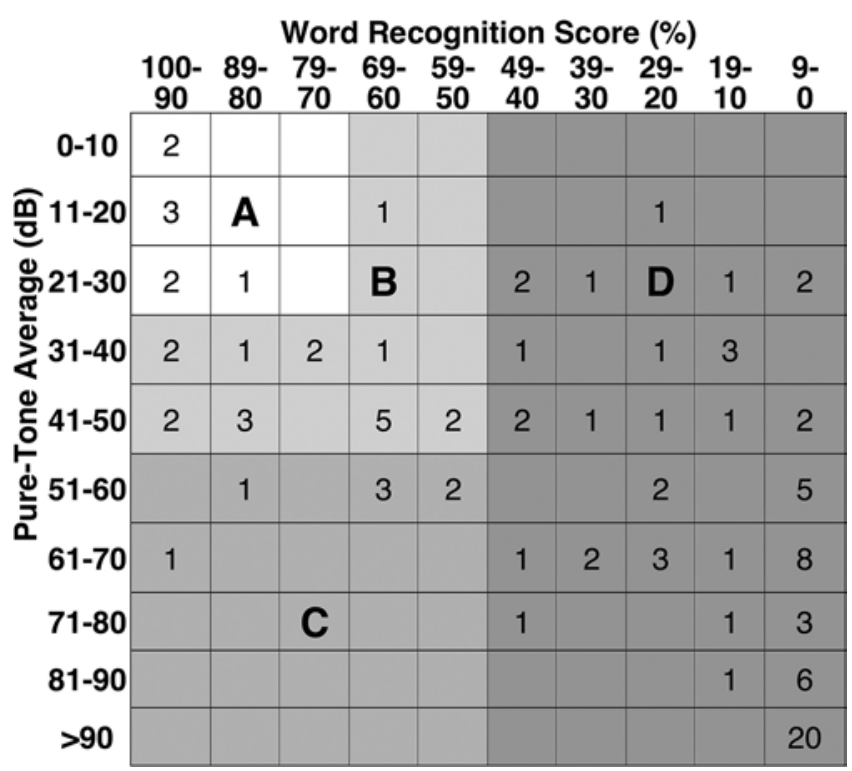

FIG. 1. Preoperative hearing scattergram detailing PTA and WRS for all patients. Preoperatively $74.8 \%$ of patients did not have serviceable hearing (A or B) and only $7.5 \%$ had good hearing $(A)$.

was recommended more frequently on an individualized basis.

\section{Statistical Analysis}

Data obtained from the database were extracted into an Excel file and then imported into a statistical program (SPSS; IBM) for analysis. Both descriptive and inferential statistical analyses were performed. Comparisons between various groups used nonparametric procedures, as there was often a considerable difference in sample size between groups, with one group having very small numbers of patients. For categorical variables, the Fisher's exact test was used for a $2 \times 2$ table; for larger tables, cell sizes were typically too small for statistical analysis, and, when possible, data were regrouped into two categories. For interval-level data, the Mann-Whitney U-test was used in comparisons between groups and Pearson correlation for the relationship between two variables. For all analyses, the criterion for statistical significance was set at $\mathrm{p} \leq 0.05$, two-tailed test.

\section{Results \\ Complications}

Operative complications are presented in Table 2. There were no deaths and no cases of meningitis or wound infection. Five patients (4.6\%) suffered postoperative cerebrospinal fluid (CSF) leaks. Four of these patients, who had CSF rhinorrhea, were treated with blind sac closure of the external auditory canal and direct packing of the eustachian tube. ${ }^{15}$ One patient $(0.9 \%)$, in whom a leak developed through the wound, was treated with oversewing of the wound and lumbar drainage, which resolved the leakage. One patient $(0.9 \%)$, who underwent MRI in the postoperative period due to headache, developed thrombosis of the sigmoid sinus and was treated with 6 months of an-
TABLE 2. Summary of complications and disposition

\begin{tabular}{|c|c|}
\hline Complication or Disposition & No. of Patients (\%) \\
\hline Mortality & $0(0)$ \\
\hline Meningitis & $0(0)$ \\
\hline CSF leak & $5(4.6)$ \\
\hline Treated by blind sac closure of EAC & $4(3.7)$ \\
\hline Treated by oversewing \& lumbar drainage & $1(0.9)$ \\
\hline Sigmoid sinus thrombosis & $1(0.9)$ \\
\hline \multicolumn{2}{|l|}{ Discharge disposition } \\
\hline Home or hotel & $107(100)$ \\
\hline Inpatient rehabilitation or long-term care & $0(0)$ \\
\hline
\end{tabular}

$\mathrm{EAC}=$ external auditory canal.

ticoagulation therapy, which led to resolution of headache and no further sequelae. Because postoperative imaging is not part of our routine protocol, it is possible that other patients developed asymptomatic sinus thrombosis. All patients were discharged directly from the inpatient hospital to home or a hotel. None required inpatient rehabilitation or convalescent care.

\section{Pathology and Tumor Control}

One hundred patients (93.4\%) were found intraoperatively to have schwannomas that were of eighth cranial nerve origin (VS). The pathology of all tumors is detailed in Table 3. Of the 100 cases of VS, 97 (97.0\%) were resected in their gross entirety. One-year postoperative MR images were available for 70 of these patients, and none showed evidence of residual or recurrent tumor. The three other VS tumors were treated with radical subtotal resections, with a maximum of 3-mm-linear tumor left adherent to the facial nerve. Two of these patients underwent annual MRI postoperatively, and they both showed no evidence of abnormal enhancement at the last follow-up 24 and 36 months after surgery. The third patient, age 74 years at the time of treatment, has refused postoperative imaging. As defined by both the absence of radiographic disease and need for additional treatment, the short-term (1-year) tumor control rate for intraoperatively proven VS was $100 \%$. By the most stringent criteria (gross-total resection, absence of radiographic disease, and no additional treatment), the tumor control rate was $95.6 \% \%$ (n $=64$ of 67 ).

TABLE 3. Summary of tumor pathologies

\begin{tabular}{lc}
\hline \multicolumn{1}{c}{ Pathology } & No. of Patients $(\%)$ \\
\hline Vestibular schwannoma & $100(93.4)$ \\
\hline Meningioma & $2(1.9)$ \\
\hline Facial nerve schwannoma & $1(0.9)$ \\
\hline Lipomatous choristoma & $1(0.9)$ \\
\hline Hemangioma & $1(0.9)$ \\
\hline Metastatic carcinoma & $1(0.9)$ \\
\hline Large-cell lymphoma & $1(0.9)$ \\
\hline
\end{tabular}




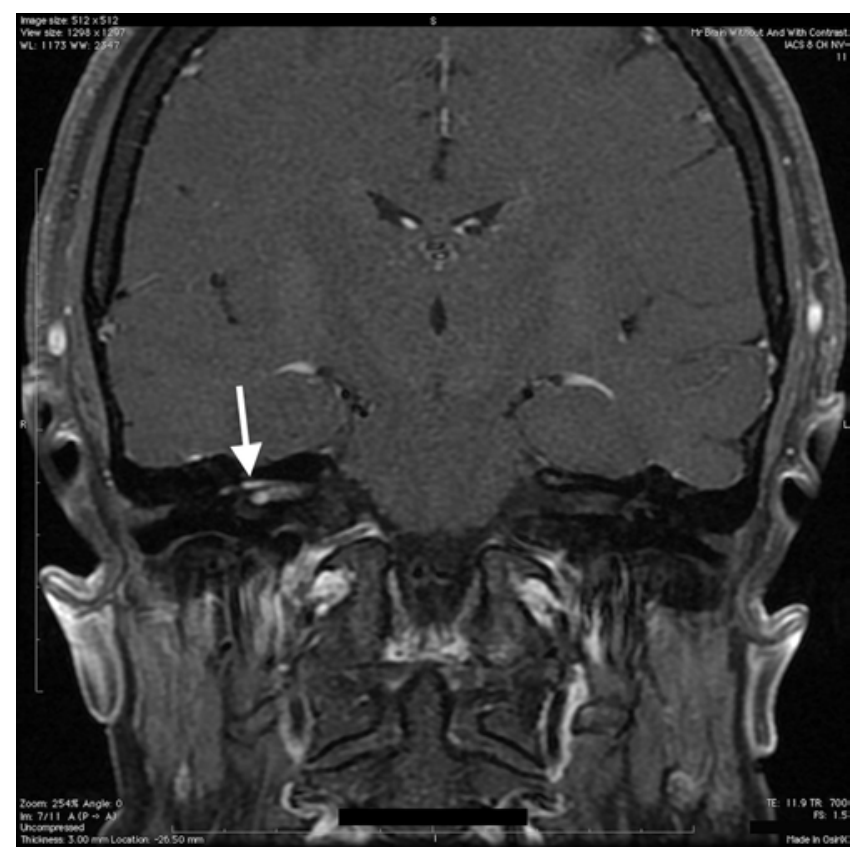

FIG. 2. Coronal contrast-enhanced T1-weighted MR image of a facial nerve schwannoma showing enhancement along the labyrinthine portion of the facial nerve (arrow).

One patient was found to have a schwannoma that clearly originated from the facial nerve. This tumor was partially resected. The residual tumor was subsequently seen to enlarge, and the patient underwent Gamma Knife radiosurgery 20 months after resection. In hindsight, the preoperative MR images obtained in this patient did show suspicious enhancement along the labyrinthine portion of the facial nerve (Fig. 2).

Two patients were found to have meningiomas, both WHO Grade I. Both lesions were resected in gross entirety, although proximity to the facial nerve did not allow for complete resection or coagulation of the dural base in either case. Both of these patients have had at least 2 follow-up MRI studies showing no evidence of residual or recurrent tumor 36 and 16 months after surgery. One example of a meningioma is shown in Fig. 3. There was one lipomatous choristoma and one hemangioma. Both pre- and postcontrast MRI studies of the choristoma were performed with fat saturation, and the MRI study of the hemangioma was of poor quality, suggesting that both tumors may have been properly diagnosed had the quality of the imaging been better. These lesions were both resected in their gross entirety, and neither patient had evidence of recurrent or residual tumor on 1-year postoperative MRI study.

Two patients, both of whom presented initially with intracanalicular tumors, were found to have malignant disease. One had metastatic carcinoma, which was subsequently found to originate from the breast, that was resected partially, and although local control was achieved after fractionated craniospinal irradiation, the patient died of systemic disease 20 months postoperatively. The other had large-cell lymphoma that was resected in its gross en-

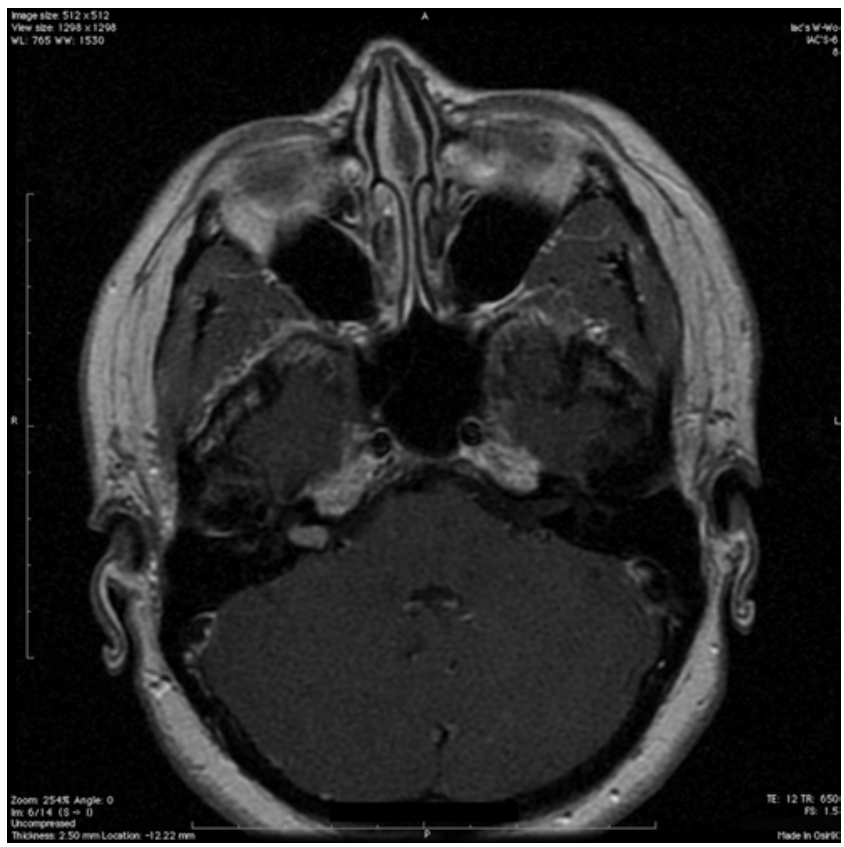

FIG. 3. Axial contrast-enhanced T1-weighted MR image of an intracanalicular meningioma. None of the meningiomas showed evidence of a dural tail or other imaging characteristics typical of meningioma. In all cases of meningioma, the IAC was neither expanded nor narrowed. The preoperative diagnosis was VS for all cases.

tirety. Following appropriate systemic treatment, this patient remains in remission without evidence of recurrent disease 6 years after surgery.

Excluding malignant tumors, the overall tumor control as defined by having no need for further treatment was $99.0 \%(n=104$ of 105). As defined by MRI absence of disease, the tumor control at 1 year was $98.7 \%$ ( $n=74$ of 75). Of course, these are short-term results. On the other hand, it should be noted that no patient who underwent gross-total resection of a benign lesion had evidence of residual or recurrent disease on follow-up MRI.

\section{Facial Nerve}

There were 105 patients with benign disease. Immediately after surgery, 101 patients $(96.2 \%)$ maintained normal function, while $3(2.9 \%)$ had mild facial weakness (HB Grade II/VI) and $1(1.0 \%)$ had more severe weakness (HB Grade IV/VI). Deterioration in facial nerve function was seen in an additional 7 patients, while 94 patients $(89.5 \%)$ maintained normal facial nerve function during the entire follow-up period; the worst facial nerve status was HB Grade II/VI in 7 patients (6.7\%), HB Grade III/VI in two patients $(1.9 \%)$, and HB Grade V/VI in two patients (1.9\%).

For patients with benign disease, late facial nerve function was normal in 103 patients $(98.1 \%)$. One patient $(1.0 \%)$ had mild facial nerve weakness (HB Grade II/VI), and one patient $(1.0 \%)$ had moderate facial nerve weakness (HB Grade III/VI). No patient had severe facial weakness ( $\geq$ HB Grade IV/VI) at the time of late follow-up.

Of the two patients found to have malignant disease, 
one, with large-cell lymphoma, maintained normal function throughout the entire follow-up period, while the other, with metastatic breast cancer, developed mild facial weakness (HB Grade II/VI) immediately after surgery, which persisted through the entire follow-up period.

\section{Predictive Factors}

Statistical analyses were performed in an attempt to identify factors related to pathology and to outcome. Given the small number of patients who were found to have pathology other than VS and the small number of individuals with nonnormal postoperative facial nerve function, all such statistical analyses must be viewed with caution because significance would be difficult to establish, as would generalizability.

None of the 7 patients who were found to have a tumor other than a VS had serviceable hearing prior to surgery, and there was a significant difference in preoperative PTA as well as a borderline finding for a difference in WRS ( $p$ $\leq 0.05$ and $\mathrm{p} \leq 0.09$, respectively). Mean PTA was $59.3 \mathrm{~dB}$ for the VS group and $82.9 \mathrm{~dB}$ for the non-VS group, with WRSs of $33.6 \%$ and $13.7 \%$, respectively. In addition, tumor extension into the CPA tended to be greater in non-VS patients versus VS patients ( $0.90 \mathrm{vs} 0.73 \mathrm{~cm}$ ), although this difference did not achieve statistical significance. For the 100 VS patients, preoperative WRSs tended to be better in the 3 patients who ended up having less than gross-total removal (mean score $74.7 \%$ ) than for those in whom total removal was possible (mean score $32.3 \%$ ) ( $\mathrm{p} \leq 0.06$ ). Total tumor size and CPA size were not significantly correlated with preoperative hearing.

\section{Discussion}

We present a series of more than 100 consecutive small VS treated via the TL approach. Outcomes were excellent, including avoidance of complications, tumor control, and facial nerve results. Of course, the TL approach is hearing destructive, so hearing results do not compare favorably with other treatment options. This fact must be taken in the context of VS, in which a preponderance of patients have poor hearing outcomes regardless of treatment. Based on these results, TL resection should be considered a very attractive option for the treatment of select patients with small VSs.

\section{Tumor Pathology}

Over 5\% of our patients with a preoperative diagnosis of VS were found to harbor tumors of other types. While this number seems high, our experience has been that small tumors are more likely to be misdiagnosed than larger tumors, likely due to the fact that MR images of small structures contain less information.

The most common type of other tumor found unexpectedly was meningioma. Patients with meningiomas are typically offered similar treatment options as those with VSs. Other types of pathology found include a facial schwannoma, a choristoma, a hemangioma, and malignant tumors. Poor quality or technically insufficient images may have played a role in these misdiagnoses. While we do not perform temporal bone CT scanning,
CT could be useful for showing other types of pathology, such as calcification in meningiomas or hemangiomas or widening of the fallopian canal of the facial nerve in facial schwannomas. It is beyond the scope of this report to calculate the cost/benefit ratio of repeating scans when the initial ones are poor in quality or of obtaining additional types of imaging, but it is likely that at least several of these operations could have been avoided with better preoperative imaging.

Specific note must be made regarding the diagnosis of two malignancies in this series. In neither case was there clear indication of the presence of malignant disease preoperatively. Imaging was typical of VS, there were no other intracranial abnormalities, and facial nerve function remained normal preoperatively. Indeed, in the case of the lymphoma, which was resected entirely, the diagnosis was not suspected until pathological examination was performed after the tumor had already been resected.

Key to good outcomes is recognizing unexpected pathology intraoperatively when it does occur. In addition, the finding of other pathology does have implications regarding the choice of stereotactic irradiation, since with this treatment a pathological specimen is not obtained. In certain instances, such as malignancies, delays in diagnosis may have implications beyond local issues such as cranial nerve function.

\section{Tumor Control}

One major limitation of this study is that we do not present long-term data regarding tumor control following TL resection. Indeed, our standard protocol for patients confirmed intraoperatively to have VS is to recommend follow-up MRI at 1 and 5 years postoperatively. Too few of our patients have 5-year follow-up to report, and a number of them have no follow-up MR images at all. Nevertheless, we have not seen residual or recurrent tumor in any patient who has had MRI follow-up after gross-total resection of tumor. Even in the few patients with less-than-total tumor resection, tumor control rates are excellent, with only a single tumor, a facial nerve schwannoma, showing subsequent growth.

Certainly, more long-term follow-up will be needed to determine overall tumor control rates. The TL approach has several strong advantages over other means of VS treatment. This approach provides direct and wide visualization of the IAC from the meatus to the fundus. In addition, the vestibulocochlear nerve can be resected together with the tumor, thus allowing for a more aggressive "margin." While we would certainly advocate for less than near-total resection of tumor in the interest of facial nerve preservation, this was necessary in very few of these patients with small tumors.

As is also our personal experience, the literature shows that there is always a chance of tumor recurrence with surgery for attempted hearing preservation, and there is always a chance of failure of tumor control with stereotactic radiotherapy., ${ }^{1,29,39,54}$ Claims about tumor control rate after stereotactic radiotherapy are also criticized due to failure to prove tumor growth prior to treatment. ${ }^{5}$ Furthermore, the choice of stereotactic radiotherapy arguably remains problematic for young patients since the very 
long-term effects of irradiation of schwannomas are yet to be revealed.

Since VS typically grow very slowly if at all and since no claim can be made regarding improving hearing outcomes over natural history, we find no logical reason to advocate for TL resection of newly diagnosed VS unless there are extenuating factors, such as intractable vestibulopathy or strong patient preference.

Some patients are inevitably lost to long-term followup following VS treatment. Although not captured in our database, a number of our patients chose surgical resection because of claustrophobia and aversion to MRIs. Although failure to obtain follow-up imaging is not ideal and is against recommendations, it is probably especially to these patients' benefit to undergo the treatment that provides the lowest likelihood of needing subsequent intervention due to tumor recurrence or failure of tumor control.

Regarding tumor control, one interesting finding is the trend toward a higher likelihood of less than total tumor resection among VS patients with better preoperative hearing. Since the rationale for performing less than total resection in this series is universally tumor adherence to the facial nerve, this finding suggests that, at least for small tumors, poor preoperative hearing predicts easier facial nerve dissection. A possible explanation for this is that tumors originating from the inferior vestibular nerve are more likely to affect hearing earlier and that these same tumors are also more distant from the facial nerve. While in our series, preoperative hearing was not correlated with facial nerve outcome, in the hands of less experienced surgeons, results could be different.

\section{Facial Nerve}

In this series, over $99 \%$ of patients who were confirmed intraoperatively to have benign disease had good long-term facial nerve function, and over $98 \%$ had normal function. These results speak for themselves and virtually equal or exceed the results of previously reported series of VS patients treated by any modality. $3,4,12,19,25,35,44,58$ Furthermore, relative recurrence rates must be factored into calculations of long-term facial nerve outcome given the fact that patients treated by other modalities are more likely to require additional treatment, and this additional treatment carries further risk to the facial nerve. ${ }^{17,18,42}$

Just over $10 \%$ of patients did develop some degree of temporary facial weakness, although in the majority of these patients weakness was mild (HB Grade II/VI). The potential for temporary facial weakness is greater with microsurgery than with stereotactic radiotherapy, which must be discussed with patients. With appropriate counseling and expectations, temporary weakness does not likely impact outcomes significantly. A subset of patients, however, may not tolerate temporary weakness, and some of these patients may be better treated with stereotactic radiotherapy.

It is to be expected that these facial nerve results cannot be achieved by most novice VS surgeons. A number of studies have demonstrated a significant learning curve of between 40 and 100 cases..$^{14,16,56}$ Most of the neurotologists involved in the cases reported in this series had surgical experience that exceeded this threshold, and the primary neurosurgeon had performed over 300 VS resections via the TL approach (including tumors of all sizes) prior to 2008. Although this series shows that risks can be mitigated, it is critical to stress that for VS treatment it is impossible to eliminate facial nerve risk entirely. This fact remains a tenet of the care of VS patients.

\section{Hearing}

Clearly one disadvantage of the TL approach is the inability to preserve hearing. The otic capsule is violated and hearing is sacrificed before the tumor is exposed. In reality, however, this is only a true disadvantage in patients who have both good hearing before treatment and the real possibility that such hearing can be preserved in the course of natural history or treatment via other methods. In this series, only about one in four patients had serviceable hearing and fewer than one in ten patients had good hearing prior to surgery.

Data suggest that the best option for hearing preservation with VS is observation. The best natural history data originate from Denmark, where population-based statistics are available..$^{51,53}$ Patients with normal hearing (speech discrimination score $100 \%$ ) tend to maintain good hearing (class A) for many years. Patients with less than normal hearing (speech discrimination score $<100 \%$ ), however, are likely to lose serviceable hearing more rapidly.

Very good outcomes for hearing have been reported with stereotactic radiotherapy. ${ }^{34,41}$ Careful review of these reports shows that only a subset of patients undergoing treatment have long-term audiometric results. Probably the best series detailing long-term hearing results after stereotactic radiosurgery for VS was published by the Mayo Clinic. ${ }^{8}$ This report shows that when nearly all patients undergo long-term audiological testing, most are shown to have lost serviceable hearing.

Microsurgical options for the treatment of small VS also include resection via the retrosigmoid or middle fossa routes. Each of these offers the opportunity of hearing preservation. Again, however, results are variable with substantial risks of hearing loss. ${ }^{2,31,40,46}$ In addition, it is important to be mindful of the fact that tumor configuration plays a significant role in the chances of hearing preservation, with tumors impacted in the fundus of the IAC typically faring more poorly in terms of hearing preservation. ${ }^{20}$

While most patients in our series presented with poor hearing at the time of treatment, a subset of patients did have audiologically good or serviceable hearing. While our data did not capture individual reasons for why the choice was made to operate on these patients via the TL route, there are several possible explanations. First, as noted above, we felt that the configuration of some tumors made the possibility of hearing preservation extremely unlikely. Second, some patients had subjectively poor hearing despite good results on audiological testing. Third, several patients chose to undergo TL resection with the understanding that it was the most definitive operation with the lowest chance of needing subsequent treatment. On occasion, the patient's choice was not entirely aligned with the recommendations of the treating surgeons.

One thing that can be stated with certainty is that, for VS treatment, the only type of series in which it is abso- 
lutely certain what the hearing results are for every patient is one following TL resection.

\section{Quality of Life}

Traditionally, VS outcomes have been measured primarily in terms of complications, facial nerve, and hearing. There is, however, a growing body of literature demonstrating the importance of quality of life (QOL). ${ }^{10,43,48} \mathrm{~A}$ major limitation of this report is the absence of QOL data, which were not captured by our prospective database. QOL studies demonstrate that other factors, most notably dizziness and headache, play a more important role in patient outcome than previously thought. Indeed, these more subjective factors may be more significant than even facial nerve function and hearing.

Dizziness and balance disturbance are common complaints independent of method of treatment. ${ }^{9}$ Vestibulopathy cannot be easily measured or quantified. With surgical treatment, vestibular symptoms improve in some patients and worsen in others, and patients with worse vestibulopathy preoperatively are more likely to improve..$^{21}$ For dizziness caused by other types of pathology, such as Ménière's disease, obliteration of the affected peripheral vestibular system is an accepted treatment. ${ }^{13}$ Thus TL resection may be a particularly attractive option for patients with VS suffering from significant vestibular symptoms.

Headaches are another common complaint among VS patients regardless of method of treatment. ${ }^{9}$ Furthermore, there is extensive literature regarding potentially disabling headaches following retrosigmoid resection of VS.11,24,47 With the TL approach, suboccipital muscles are not elevated or transected, the greater occipital nerve is not put at risk, and all bone drilling occurs prior to opening the dura. These factors may serve to mitigate the chance of patients developing severe headaches after undergoing TL resection of tumors.

Finally, even in terms of hearing, patients with unilateral hearing loss report that hearing in noisy environments impacts QOL more than hearing in quiet environments. ${ }^{57}$ Since audiograms are carried out in a quiet sound booth, the correlation between routine audiometric results and QOL remains unknown. Many patients with unilateral hearing loss report subjectively poor hearing in daily life despite measured serviceable hearing. ${ }^{22}$ Further study in this area is needed.

\section{Conclusions}

TL resection of small VS provides excellent results in terms of complication avoidance, tumor control, and facial nerve outcomes. This is a hearing-destructive operation and is not advocated for all patients. Factors that would favor resection via the TL approach include tumors proven to be growing, young patients, patients with poor hearing, patients with significant vestibulopathy, and patients with claustrophobia or aversion to MRIs. Choice of treatment should be individualized.

\section{Acknowledgments}

The authors thank Karen I. Berliner for statistical analysis and for editorial assistance.

\section{References}

1. Ahmad RA, Sivalingam S, Topsakal V, Russo A, Taibah A, Sanna M: Rate of recurrent vestibular schwannoma after total removal via different surgical approaches. Ann Otol Rhinol Laryngol 121:156-161, 2012

2. Ansari SF, Terry C, Cohen-Gadol AA: Surgery for vestibular schwannomas: a systematic review of complications by approach. Neurosurg Focus 33(3):E14, 2012

3. Badakhshi H, Graf R, Böhmer D, Synowitz M, Wiener E, Budach V: Results for local control and functional outcome after linac-based image-guided stereotactic radiosurgery in 190 patients with vestibular schwannoma. J Radiat Res (Tokyo) 55:288-292, 2014

4. Boari N, Bailo M, Gagliardi F, Franzin A, Gemma M, del Vecchio A, et al: Gamma Knife radiosurgery for vestibular schwannoma: clinical results at long-term follow-up in a series of 379 patients. J Neurosurg 121 Suppl:123-142, 2014

5. Bassim MK, Berliner KI, Fisher LM, Brackmann DE, Friedman RA: Radiation therapy for the treatment of vestibular schwannoma: a critical evaluation of the state of the literature. Otol Neurotol 31:567-573, 2010

6. Ben Ammar M, Piccirillo E, Topsakal V, Taibah A, Sanna $\mathrm{M}$ : Surgical results and technical refinements in translabyrinthine excision of vestibular schwannomas: the Gruppo Otologico experience. Neurosurgery 70:1481-1491, 2012

7. Calzada AP, Go JL, Tschirhart DL, Brackmann DE, Schwartz MS: Cerebellopontine angle and intracanalicular masses mimicking vestibular schwannomas. Otol Neurotol 36:491-497, 2015

8. Carlson ML, Jacob JT, Pollock BE, Neff BA, Tombers NM, Driscoll CL, et al: Long-term hearing outcomes following stereotactic radiosurgery for vestibular schwannoma: patterns of hearing loss and variables influencing audiometric decline. J Neurosurg 118:579-587, 2013

9. Carlson ML, Tveiten ØV, Driscoll CL, Boes CJ, Sullan MJ, Goplen FK, et al: Risk factors and analysis of long-term headache in sporadic vestibular schwannoma: a multicenter cross-sectional study. J Neurosurg 123:1276-1286, 2015

10. Carlson ML, Tveiten ØV, Driscoll CL, Goplen FK, Neff BA, Pollock BE, et al: Long-term quality of life in patients with vestibular schwannoma: an international multicenter crosssectional study comparing microsurgery, stereotactic radiosurgery, observation, and nontumor controls. J Neurosurg 122:833-842, 2015

11. Catalano PJ, Jacobowitz O, Post KD: Prevention of headache after retrosigmoid removal of acoustic tumors. Am J Otol 17:904-908, 1996

12. Chopra R, Kondziolka D, Niranjan A, Lunsford LD, Flickinger JC: Long-term follow-up of acoustic schwannoma radiosurgery with marginal tumor doses of 12 to $13 \mathrm{~Gy}$. Int J Radiat Oncol Biol Phys 68:845-851, 2007

13. Diaz RC, LaRouere MJ, Bojrab DI, Zappia JJ, Sargent EW, Shaia WT: Quality-of-life assessment of Ménière's disease patients after surgical labyrinthectomy. Otol Neurotol 28:74-86, 2007

14. Elsmore AJ, Mendoza ND: The operative learning curve for vestibular schwannoma excision via the retrosigmoid approach. Br J Neurosurg 16:448-455, 2002

15. Fayad JN, Schwartz MS, Slattery WH, Brackmann DE: Prevention and treatment of cerebrospinal fluid leak after translabyrinthine acoustic tumor removal. Otol Neurotol 28:387-390, 2007

16. Foroughi M, Pitkäniemi J, Nannapaneni R, Nath F: Excision of vestibular schwannomas-is there a learning curve and how best to demonstrate it? Br J Neurosurg 24:547-554, 2010

17. Friedman RA, Brackmann DE, Hitselberger WE, Schwartz MS, Iqbal Z, Berliner KI: Surgical salvage after failed irradiation for vestibular schwannoma. Laryngoscope 115:18271832,2005 
18. Gerganov VM, Giordano M, Samii A, Samii M: Surgical treatment of patients with vestibular schwannomas after failed previous radiosurgery. J Neurosurg 116:713-720, 2012

19. Ginzkey C, Scheich M, Harnisch W, Bonn V, Ehrmann-Müller D, Shehata-Dieler W, et al: Outcome on hearing and facial nerve function in microsurgical treatment of small vestibular schwannoma via the middle cranial fossa approach. Eur Arch Otorhinolaryngol 270:1209-1216, 2013

20. Goddard JC, Schwartz MS, Friedman RA: Fundal fluid as a predictor of hearing preservation in the middle cranial fossa approach for vestibular schwannoma. Otol Neurotol 31:1128-1134, 2010

21. Godefroy WP, Hastan D, van der Mey AG: Translabyrinthine surgery for disabling vertigo in vestibular schwannoma patients. Clin Otolaryngol 32:167-172, 2007

22. Gopinath B, Schneider J, Hickson L, McMahon CM, Burlutsky G, Leeder SR, et al: Hearing handicap, rather than measured hearing impairment, predicts poorer quality of life over 10 years in older adults. Maturitas 72:146-151, 2012

23. Gurgel RK, Jackler RK, Dobie RA, Popelka GR: A new standardized format for reporting hearing outcome in clinical trials. Otolaryngol Head Neck Surg 147:803-807, 2012

24. Harner SG, Beatty CW, Ebersold MJ: Headache after acoustic neuroma excision. Am J Otol 14:552-555, 1993

25. Hillman T, Chen DA, Arriaga MA, Quigley M: Facial nerve function and hearing preservation acoustic tumor surgery: does the approach matter? Otolaryngol Head Neck Surg 142:115-119, 2010

26. House JW, Brackmann DE: Facial nerve grading system. Otolaryngol Head Neck Surg 93:146-147, 1985

27. House WF: Fatalities in acoustic tumor surgery. Arch Otolaryngol 88:687-699, 1968

28. House WF, Hitselberger WE: Fatalities in acoustic tumor surgery, in House WF, Luetje CM (eds): Acoustic Tumors Volume II: Management. Baltimore: University Park Press, 1979, pp 235-264

29. Kapoor S, Batra S, Carson K, Shuck J, Kharkar S, Gandhi R, et al: Long-term outcomes of vestibular schwannomas treated with fractionated stereotactic radiotherapy: an institutional experience. Int J Radiat Oncol Biol Phys 81:647-653, 2011

30. Kondziolka D, Lunsford LD, McLaughlin MR, Flickinger JC: Long-term outcomes after radiosurgery for acoustic neuromas. N Engl J Med 339:1426-1433, 1998

31. Lassaletta L, Fontes L, Melcon E, Sarria MJ, Gavilan J: Hearing preservation with the retrosigmoid approach for vestibular schwannoma: myth or reality? Otolaryngol Head Neck Surg 129:397-401, 2003

32. Lunsford LD, Niranjan A, Flickinger JC, Maitz A, Kondziolka D: Radiosurgery of vestibular schwannomas: summary of experience in 829 cases. J Neurosurg 102 Suppl:195-199, 2005

33. Monsell EM, Balkany T, Gates G, Goldenberg RA, Meyerhoff WL, House JW: Committee on Hearing and Equilibrium guidelines for the evaluation of hearing preservation in acoustic neuroma (vestibular schwannoma). American Academy of Otolaryngology-Head and Neck Surgery Foundation, INC. Otolaryngol Head Neck Surg 113:179-180, 1995

34. Mousavi SH, Kano H, Faraji AH, Gande A, Flickinger JC, Niranjan A, et al: Hearing preservation up to 3 years after Gamma Knife radiosurgery for Gardner-Robertson class I patients with vestibular schwannomas. Neurosurgery 76:584-591, 2015

35. Murphy ES, Barnett GH, Vogelbaum MA, Neyman G, Stevens GH, Cohen BH, et al: Long-term outcomes of Gamma Knife radiosurgery in patients with vestibular schwannomas. J Neurosurg 114:432-440, 2011

36. Nonaka Y, Fukushima T, Watanabe K, Friedman AH, Sampson JH, Mcelveen JT Jr, et al: Contemporary surgical management of vestibular schwannomas: analysis of complications and lessons learned over the past decade. Neurosurgery 72 (2 Suppl Operative):ons103-ons115, 2013

37. Olivecrona H: Acoustic tumors. J Neurosurg 26:6-13, 1967

38. Panse R: Ein gliom des akustikus. Arch Ohrenheilk 61:251255,1904

39. Pollock BE, Link MJ, Foote RL: Failure rate of contemporary low-dose radiosurgical technique for vestibular schwannoma. Clinical article. J Neurosurg 119 Suppl:840-844, 2013

40. Rabelo de Freitas M, Russo A, Sequino G, Piccirillo E, Sanna $\mathrm{M}$ : Analysis of hearing preservation and facial nerve function for patients undergoing vestibular schwannoma surgery: the middle cranial fossa approach versus the retrosigmoid approach-personal experience and literature review. Audiol Neurootol 17:71-81, 2012

41. Régis J, Carron R, Park MC, Soumare O, Delsanti C, Thomassin JM, et al: Wait-and-see strategy compared with proactive Gamma Knife surgery in patients with intracanalicular vestibular schwannomas: clinical article. J Neurosurg 119 Suppl:105-111, 2013

42. Roche PH, Khalil M, Thomassin JM: Microsurgical removal of vestibular schwannomas after failed previous microsurgery. Prog Neurol Surg 21:158-162, 2008

43. Ryzenman JM, Pensak ML, Tew JM Jr: Patient perception of comorbid conditions after acoustic neuroma management: survey results from the acoustic neuroma association. Laryngoscope 114:814-820, 2004

44. Sameshima T, Fukushima T, McElveen JT Jr, Friedman AH: Critical assessment of operative approaches for hearing preservation in small acoustic neuroma surgery: retrosigmoid vs middle fossa approach. Neurosurgery 67:640-645, 2010

45. Samii M, Matthies C: Management of 1000 vestibular schwannomas (acoustic neuromas): the facial nerve-preservation and restitution of function. Neurosurgery 40:484494, 694-695, 1997

46. Sanna M, Khrais T, Russo A, Piccirillo E, Augurio A: Hearing preservation surgery in vestibular schwannoma: the hidden truth. Ann Otol Rhinol Laryngol 113:156-163, 2004

47. Schaller B, Baumann A: Headache after removal of vestibular schwannoma via the retrosigmoid approach: a long-term follow-up-study. Otolaryngol Head Neck Surg 128:387395, 2003

48. Schwartz MS, Riddle SA, Delashaw JB Jr, Horgan MA, Kel$\operatorname{logg}$ JX, McMenomey SO: Quality of life following acoustic neuroma surgery. Neurosurg Focus 5(3):e3, 1998

49. Slattery WH: The translabyrinthine approach to the skull base, in Friedman RA, Slattery WH, Brackmann JN, et al (eds): Lateral Skull Base Surgery: The House Clinic Atlas. New York: Thieme, 2012, pp 47-66

50. Stangerup SE, Cayé-Thomasen P, Tos M, Thomsen J: The natural history of vestibular schwannoma. Otol Neurotol 27:547-552, 2006

51. Stangerup SE, Thomsen J, Tos M, Cayé-Thomasen P: Longterm hearing preservation in vestibular schwannoma. Otol Neurotol 31:271-275, 2010

52. Stangerup SE, Tos M, Cayé-Thomasen P, Tos T, Klokker $\mathrm{M}$, Thomsen J: Increasing annual incidence of vestibular schwannoma and age at diagnosis. J Laryngol Otol 118:622-627, 2004

53. Stangerup SE, Tos M, Thomsen J, Cayé-Thomasen P: Hearing outcomes of vestibular schwannoma patients managed with 'wait and scan': predictive value of hearing level at diagnosis. J Laryngol Otol 124:490-494, 2010

54. Sughrue ME, Kaur R, Rutkowski MJ, Kane AJ, Kaur G, Yang I, et al: Extent of resection and the long-term durability of vestibular schwannoma surgery. J Neurosurg 114:12181223,2011

55. Tos M, Thomsen J, Harmsen A: Results of translabyrinthine 
removal of 300 acoustic neuromas related to tumour size. Acta Otolaryngol Suppl 452:38-51, 1988

56. Wang AY, Wang JT, Dexter M, Da Cruz M: The vestibular schwannoma surgery learning curve mapped by the cumulative summation test for learning curve. Otol Neurotol 34:1469-1475, 2013

57. Wie OB, Pripp AH, Tvete O: Unilateral deafness in adults: effects on communication and social interaction. Ann Otol Rhinol Laryngol 119:772-781, 2010

58. Yamakami I, Ito S, Higuchi Y: Retrosigmoid removal of small acoustic neuroma: curative tumor removal with preservation of function. J Neurosurg 121:554-563, 2014

59. Yaşargil MG, Fox JL: The microsurgical approach to acoustic neurinomas. Surg Neurol 2:393-398, 1974

\section{Disclosures}

Dr. Wilkinson has received clinical or research support for the study from Med-EL US and from Cochlear Americas; he reports being a consultant for Nurotron Biotechnology.

\section{Author Contributions}

Conception and design: Schwartz. Acquisition of data: Schwartz. Analysis and interpretation of data: Schwartz, Lekovic. Drafting the article: Schwartz. Critically revising the article: all authors. Reviewed submitted version of manuscript: all authors. Approved the final version of the manuscript on behalf of all authors: Schwartz.

\section{Supplemental Information \\ Videos}

Video 1. https://vimeo.com/210292366.

\section{Correspondence}

Marc S. Schwartz, Department of Neurosurgery, House Clinic, 2100 West Third St., Los Angeles, CA 90057. email: mschwartz@ houseclinic.com. 